POETRY

\title{
We Still Need Rainbows
}

Shoshanna Beale

I know it's such a cliché-I can see

your eyes roll at the title as you drop

my page with a sneer but I swear it's truetoday as I walked in the rain and wind, the cold, bitter as my emotional state, when a pane flew off a fence with a twang and I looked into the grey miserable sky and saw it-a double rainbow above clouds that looked smoothed over with a hairbrush while people came out of their houses to stare into the sky and slowly smile and I thought sometimes it takes a cliché to make life just that tiny bit better. 